Received: May 02, 2017

Accepted: May 17, 2017

Published: June 13, 2017

\section{Pseudomona Chondritis and Ear Piercing Pseudomona and Piercing}

Julieta Ruiz Beguerie $^{1^{*}}$ and Angeles Petersen ${ }^{2}$

${ }^{1}$ Department of Medicine, Division of Dermatology, Austral University Hospital, Austral University, Buenos Aires, Argentina

${ }^{2}$ Department of Surgery, Division of Plastic Surgery, Fernandez Hospital, Buenos Aires, Argentina

*Corresponding author: Julieta Ruiz Beguerie, Department of Dermatology, Austral University Hospital, Austral University, Buenos Aires, Argentina, E-mail: jruiz@cas.austral.edu.ar

\section{Abstract}

We describe a case of perichondritis by Pseudomona aeruginosa after piercing of the right posterior third of the ear pinna cartilage (high ear piercing) in an otherwise healthy Caucasian adolescent female of 16 years old at a local shop. Based on the tissue sample culture, she was successfully treated with ceftriaxone after a non-respondent first treatment, minimizing the destruction of the ear.

A review of the history of body piercing, complications, risk factors, and treatments is presented with this increasing practice around Western cultures. Bodypiercing-associated cutaneous bacterial infections have been reported with increasing frequency, being Staphylococcus aureus the cause in the majority of the cases. Unlike Staphylococcus, Pseudomona is usually more aggressive and non-respondant to cephalexin or Trimethoprim/Sulfamethoxazole (TMP/SMX). Complications in the piercing site, especially in regions with low blood supply, such as the ear cartilage as in this case, may occur . Hence, awareness of the precise diagnosis and aggresive adequate treatment must be installed without delay in order to minimize destruction of tissue.

\section{Keywords} tis;

Chondritis; Body Piercing; Pseudomona Chondri-

\section{Case Report}

A previously healthy 16-year-old girl had the upper portion of her right ear pierced at a local shop of tattooing and body pierc- ing. The type of body piercing earring she had was an industrial bar made of titanium and placed it in a diagonal way using a spring loaded piercing gun (Figure 1).

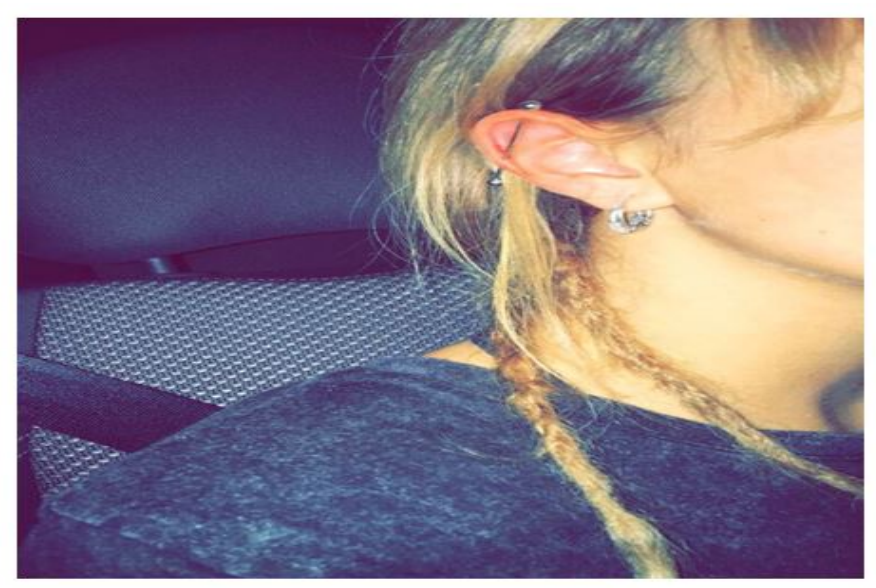

Figure 1 Right ear the same day she had the bar piercing done.

Three days after the amateur body piercing, she developed erythema and increasing pain associated with edema in the perforated area. Since day 1 , she had been cleaning the pierced area with sterile gauze embedded in saline solution. As the inflammation kept increasing, she was seen at another hospital and unsuccessfully treated with oral cephalexin 2 grs per day for four consecutive days. Two days after, the patient finally underwent incision and drainage surgery of the abscess, which was repeated once again during the following week. (Figure 2) This practice included drainage of pus and blood. Pus sample was inmediately sent in a sterile specimen container to the microbiology laboratory for typification and culture. In 24 hs we received the diagnosis of Pseudomona aeruginosa. 


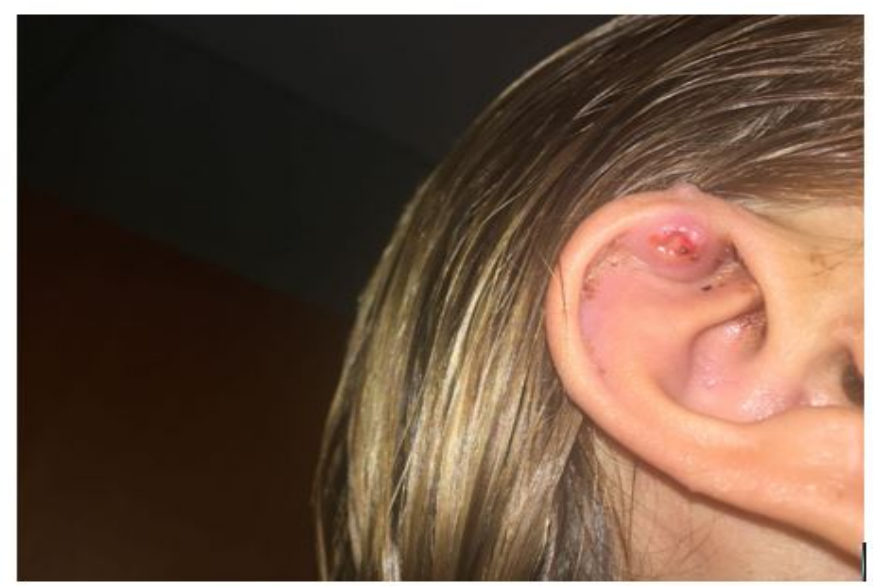

Figure 2 Abscess in the right ear 5 days after the piercing was done.

After the first drainage surgery, she received oral antipseudomonal antibiotics; ciprofloxacine 400mg every 12 hs for 3 weeks with subsequent resolution.

"High ear piercing" increases infection morbidity, especially with Pseudomonas aeruginosa and its antibiotic resistance.

\section{Discussion}

Body piercing has become a fashionable trend in adolescents and young adults, being the female group the $87.5 \%$ of the customers (mean age 18.7 yrs /- 7.6 yrs, range: 11-49 yrs) as an adornment or as a self-expression [1]. A 2010 survey carried out by the Pew Research Center in the USA found that among Millennials, 1 in 4 has a body piercing in some place other than the classic earlobe. Ear lobes and ear cartilages are the most commonly pierced places. Usually, the procedure is carried out without adequate local hygiene or anesthesia, with the passage of a needle , most times using a gun through the region and later insertion of an object into this cavity. The material of the earings inserted varies from titanum to steel trying to avoid nikel because of high percentage of allergies. According to a study led by Van Wiik, the pattern of injury was similar with all piercing techniques, showing perichondrium stripped from the cartilage around the pin tract, with most damage present on the exit site [2].

Pseudomonas aeruginosa, an opportunistic pathogen, is member of the Gamma Proteobacteria class of Bacteria. It is a Gramnegative, aerobic rod-shaped belonging to the bacterial family Pseudomonadaceae and a free-living bacterium, commonly found in soil and water. Several epidemiological studies track its occurrence as a nosocomial pathogen and indicate that antibiotic resistance is increasing in clinical isolates.Invasion of the skin and cartilage poses the potential for infection, inflammation and fluid accumulation, which may exacerbate an already tenuous blood supply to the ear cartilage [3]. This might end in severe ear deformity and impaired accoustic funneling of the external ear, specially if performed in substerile conditions. $1 \mathrm{~A}$ bacterial infection at the site of the piercing is the most common risk, which increments according to the area in the ear perforated. Other risks to take into account before bodypiercing are: allergic skin reactions to the jewelry used, hypertrophic scarring, site bleeding, tearing if it gets caught on something and jewelry rejection or migration.

Perichondritis or perichondral inflammation is a severe and recently very frequent complication of this body piercing trend. The characteristic sign is ear pinna redness. The ear lobe does not have cartilage, so it has not been found such complications. Pain, usually intense, may co-exist with fever. If treatment is delayed for unawareness or carelessness, there may be widespread pinna edema and infection becoming a subperichondral abscess with possible cartilage ischemic necrosis. When abscess arises with a fluctuation aspect, there is the urgent need for surgical drainage as what happened with our patient, with necrosed tissue debridement and broad spectrum intravenous or oral antibiotic treatment (third generation cefalosporins, fluoroquinolones and nitroimidazole) and antibiogram culture of the exudate sample taken. Second intention healing process often causes an ear deformity known as "cauliflower ear". The destruction of ear cartilage in cases of unfavorable development, associated with a scar, needs plastic reconstruction.

A cartilaginous framework, covered by subcutaneous tissue and skin, forms the ear pinna. Anteriorly, the skin is firmly adhered to the cartilage, with scarce subcutaneous tissue. Posteriorly, there is more subcutaneous tissue, reducing the adherence between skin and cartilage. Cartilage nutrition is carried out by the contiguous perichondrium, and it should be preserved to avoid destruction by necrosis [4].

The main reasons for having bodypiercing in history , vary from religious, rebellion or mysticism to initiation rituals or rites of passage from teenage years to adulthood from Asia to America [4]. Piercing dates back before Bible times. In 1991, the oldest mummified body in the world was found frozen in an Austrian Glacier, which showed the body to be over 5,000 years old. The body had pierced ears which were probably magical purposes. Many primitive tribes believed that demons can enter the body through the ear; ear piercing could prevent that from happening, because demons and spirits were supposed to be repelled by metal. Sailors used to have an ear pierced due to the superstitious belief that doing so would improve their eyesight, keeping them safer at sea. Afterwards even when the Roman Republic grew with wealth and luxury, earrings were more popular among men than women. Julius Caesar brought back to fashion the use of rings in the ears of males. [5] In Ancient Egypt only the pharaoh was allowed to have his navel pierced and anyone else who did so was executed. Egyptians wore earrings to display their wealth and portray their beauty. Believers of Hinduism or alternative medicine believe that piercing the belly button aligns or improves function of the third chakra, the solar plexus, which controls emotions, such as willpower and self-esteem, and rules organs in the torso, such as the pancreas and kidneys. In these cultures, the belly button piercing acts as a "gatekeeper" to hold positive energy inside the body while preventing negative energy from entering. "Body modification" can range from piercings and tattoos to neck accentuation or teeth sharpening.

Body piercing ending in chondritis is more common when the scalpha is invaded resulting in $100 \%$ of ear deformity in comparison when the hélix was involved (43\%) $[6,7]$.

In an investigation published in 2005 after a pseudomona out- 
break in USA after ear-piercing, of the 15 confirmed cases, nine (60\%) were hospitalized (median duration 4.4 days) and treated with intravenous/oral antibiotics. [8] In Oregon, another outbreak of Pseudomona after ear piercing was also published in JAMA by Keene and Marcus where they found after molecular subtyping pseudomonas, matching isolates from a disinfectant bottle and nearby sink in the piercing shop in a shopping mall [9].

According to a systemic review published in Laryngoscope journal in 2015, the mean duration of symptoms prior to patients seeking medical attention for this nfection was $6.1 \pm 4.1$ days, which match our case. Greater than 5 days of symptoms prior to seeking treatment was significantly more likely to result in hospitalization. Pseudomonas aeruginosa accounted for $87.2 \%$ infections. Of the patients with Pseudomonas, 92.3\% were hospitalized versus $75 \%$ of the patients infected with Staphylococcus aureus [1]. More than half of the patients were not prescribed anti-pseudomonal antibiotics on presentation [1].

Unfortunately, piercing in many countries is carried out by nonauthorized or untrained persons in street shops or shoppings, who use invasive techniques learned on the internet or magazines - There is no consensus on correct asepsis techniques, varying from benzalkonium chloride, ethylic and isopropyl alcohol to iodine solution (the best product to eliminate Pseudomonas) [10]. Potential sources of infection including the piercing gun, disinfectant solutions, and earings have to be evaluated. Strict public health control on the body piercing places is urgent, as well as specific guidelines are needed [11]. The people involved in this industry must know the anatomy of the body part where they will be working on and understand the high risk of serious infection after piercing.

Clinicians should remember that ear cartilage piercing is inherently more risky than lobe piercing, and therefore respond aggressively to potential auricular chondritis considering Pseudomonas a possible causative organism pending culture results. The consequences of delayed diagnostic and intervention, and the incorrect antibiotic selection may result in systemic infection, antibiotic resistence increase and cartilaginous collapsed with the need of ear reconstructive plastic surgery which increases emotional and financial burden for the patients and their families.

\section{References}

1. Sosin M, Weissler JM, Pulcrano M, Eduardo D. Laringoscope 2015;125:1827-1834. DOI: 10.1002/lary.25238
2. Van Wiik MP, Kummer JA, Kon M. Ear piercing techniques and their effect on cartilage, a histologic study. Journal of Plastic Reconstructive \& Aesthetic Surgery. 2008;61(1):104-109.

3. Yetkin G, Otlu B, Cicek A, Kuzucu C, Durmaz R. Clinical, microbiologic, and epidemiologic characteristics of Pseudomonas aeruginosa infections in a University Hospital, Malatya, Turkey. Am J Infect Control. 2006;34(4):188-192.

4. Fernandez A de P, Castro Neto I, Ribeiro Arias C, Ciinelli P, Jair de Carvalho e Castro, Arturo Frick Carpes, et al. PostPiercing condritis. Rev Bras Otorrinolaringol .2008;74(6):933937.

5. Marianne, Ostier. Jewels \& Women; the Romance, Magic and Art of Feminine Adornment. Horizon Press. New York. 1958.

6. Liu Z, Chokkalingam P. Piercing associated perichondritis of the pinna: Are we treating it correctly? The Journal of Laryngology \& Otology. 2013;127(5):505-508. doi:10.1017/S0022215113000248

7. G Bellaud, A Canestri, S Gallah, M Merlant, Cousseau S, Lebrette MG, et al. Bacterial chondritis complications following ear piercing. Médecine et Maladies Infectieuses. 2017;47(1):26-31. doi: 10.1016/j.medmal.2016.07.002

8. Fisher CG, Kacica MA and Bennett NM. Risk factors for cartilage infections of the ear. Am J Prev Med. 2005;29(3):204209.

9. Keene WE, Makum AC and Samadpour M. Outbreak of Pseudomonas aeruginosa infections caused by commercial piercing of upper ear cartilage. JAMA. 2004;291(8):981-985.

10. Steward GM, Thorp A and Brown L. Perichondritisa complication of high ear piercing. Pediatr Emerg Care. 2006;22(12):804-806.

11. Sandhu A, Gross M, Wylie J, Van CaeseeleP, Plourde P. Pseudomonas aeruginosa necrotizing chondritis complicating high helical ear piercing case report: clinical and public health perspectives. Can J Public Health. 2007;98(1):74-77 